\title{
My Opinions on the Theme of Amid the Mulberries, Airs of Yong, the Book of Songs
}

\author{
Hongli Wang
}

Guangdong Literature and Art Vocational College, Guangzhou Guangdong, 511400, China

Keywords: The Book of Songs, Airs of Yong, Theme

\begin{abstract}
Exploring the theme of Amid the Mulberries, Airs of Yong, the Book of Songs from "illicit intercourse". Inferring that the emotional appeal of the poetry is not "obscene" as said by predecessors but has a characteristics of fresh sweet and affectionateness through textual research on "the man in the poem", "the place in the poem".
\end{abstract}

\section{Introduction}

There is a word "illicit intercourse" in the Chinese language with the meaning of "the combination of men and and women not legal". It is originated from Amid the Mulberries, Airs of Yong, the Book of Songs according to the study. The poem as follows:

Where's golden thread to pick?

In May field where it's thick.

Who are you thinking of?

Jiang's eldest lass I love.

Would she wait for me amid mulberries,

Behind the temple tryst with me

And see me off on River Qi?

Where's golden wheat to pick?

In north field where it's thick.

Who are you thinking of?

Yi's eldest lass I love.

Would she wait for me amid mulberries,

Behind the temple tryst with me

And see me off on River Qi?

Where's mustard plant to pick?

In east field where it's thick.

Who are you thinking of?

Yong's eldest lass I love.

Would she wait for me amid mulberries,

Behind the temple tryst with me

And see me off on River Qi?

What does this poem aim at? Why are there hints about making love derived from the poem? One should still start with the poetry text itself if he/she wanted to come to a proper conclusion. Finding out the key points is more reliable.

\section{The Man in the Poem}

The author of this poem, the lyrical leading character, is a man. There is no doubt about that. 
There are three names in his singing: Meng Jiang, Meng Yi, Meng Yong. Since the ancient, the focus of the debate is, the three names belong to the same person or to different persons. It seems to me that, what the man misses is one person rather than the three women appeared in the poem. There are three reasons for this:

Firstly, the poet used three different names in order to rhyme the poem. In the era of the "the book of songs", the rule of the rhyme was not as strict as that of the later ages. While the spontaneous rhymes ancestors used roughly coincide with those of the later generations. The first four sentences of the poem take the rule of rhyming in every other line, subjecting to the flat rhyme class, "Xiang" in the second sentence of the first chapter has the same rhyme with "Jiang" in the fourth sentence, all belong to "masculing" rhyme; "Bei" of the second chapter has the same rhyme with "Yi", all belong to "post" rhyme; "Dong" of the third chapter belongs to "Dong"(the Chinese word means "east") rhyme, "Yong" belongs to "Dong"(the Chinese word means "winter") rhyme, broadly, the first "Dong" and the second "Dong" can be used as the same rhyme. Just as Mr. Zhu Zi Qing said, "I think the names of the three women are really just for the sake of rhyme".

Secondly, the preposition "at"(Chinese pinyin as "yu") is omitted in the three sentences-"Jiang's eldest lass I love", "Yi's eldest lass I love", "Yong's eldest lass I love". In ancient Chinese language, preposition "at"("yu"), combined with nouns, pronouns, together, compose prepositional objective phrase, can be omitted in some cases when modifying adjectives etc. For example, it is often mentioned in classical style of writings, the "three years older than me" is actually "three years older than at me", here the preposition "at" is omitted. So, the positive solution of three sentences should be "Jiang's eldest lass I love at", "Yi's eldest lass I love at", "Yong's eldest lass I love at", that is, woman whom he misses is another person more beautiful than the three women.

Thirdly, choose three eldest daughter of a large house in the poem as the reference object would be closer to the nature of the folk song "Feng poetry". Through the ages, all aspects such as family status of a large house somewhere were always relished in the local people. The three big misses of a large house were well known because of their outstanding appearance, naturally became the common people's topic of conversation in their leisure as well as appeared in local folk song.

All in all, undoubtedly, the author of the poem is a man, the objective he misses is an age-appropriate woman.

\section{The place in the poem}

There are four places in this poem: May field, amid mulberries, the temple, River Qi. Among them, May field and River Qi have certain references without dissent: May field is the capital of the last four Kings in the Shang dynasty as well as where the author lives. The loving affairs the poem describes just happened here. River Qi is a river of May field, a river appears for times in the Book of Songs, witnessing thevicissitudes of life of people on both sides of the river.

What Amid mulberries and the temple refer to is roughly clear, the controversies lie at the social customs related to this. Mr. Guo Mo Ruo said in studies on oracle - bone scripture that, " Amid mulberries is the place where mulberries at, the temple is an ancestral temple for religious ritual of mulberries..." I can't agree more with that. The problem is, how these two places be connected with making love?

First of all, in the ancient Chinese society, the social character and function of men tilling the farm and womenweaving are very clear. With the function of raising silkworms, mulberry leaves related to "womenweaving" are about the livelihood of the people. Therefore, in the living place of ancestors in ancient times, mulberries woods is a common landscape, while "amid mulberries" naturally refers to a place in mulberry trees. This place occupied a pivotal position in Ancients' life. So to speak, it has a meaning of emphasis when referring to "amid mulberries", no drama. According to the article of cultural interpretation of Amid Mulberries, the Book of Songs written by contemporary scholar-Ren Huisheng: mulberries in the Shang Dynasty has a sacred status, therefore there were solemn ceremonies of mulberry being held that time.

Second, the place where the ceremony of mulberry held is what Mr.Guo Mo Ruo said as " the temple for religious ritual of mulberries"-the temple. As for the object, ceremony and the meaning of 
the sacrifice ceremony, opinions vary. Recently there's a saying that is very conspicuous: according to the record of Proceedings of Government in the Different Months, a Book of Rites, "In the second month of spring, ...In this month the swallow makes its appearance. On the day of its arrival, the son of Heaven sacrifices to the first match-maker with a bull, a ram, and a boar. He goes to do so in person, with his queen and help-mates, attended by his nine ladies of honour. Peculiar courtesy is shown to those whom he has (lately) approached. Bow-cases have been brought, and a bow and arrows are given to each before (the altar of) the first match-maker."Chen Bing Liang said, "No matter what the son of Heaven did is to his the queen and maids of honour of different rank or to holy whores, in a word, a practical or symbolic making-love behavior happened in front of divinity. At the same time, the ceremony of giving bows and arrows is also a symbol of coition between men and women." He also used the sentences of "In the second month of spring, make men and women date. At that time, their coition behavior would net be prohibited." to the record of Matchmaker, Diguan, Zhouli, as verification. Regardless of how rational this saying is, just its explanation of the sentences are necessary to be discussed. Even if the ceremony of "giving bows and arrows" symbolizes coition between men and women, this coition behavior would not materially be held before god. Now that there were no material coition behaviors happening in the worship place, this place would not be called the place of commit adultery.

Third, the record in Zhouli, "'In the second month of spring, make men and women date. At that time, their coition behavior would net be prohibited. Anyone did not take the order for no reason at all will be punished", was a special policy formulated by rulers to promote reproduction, the object of which is older young men and women over the marry age. As said by rectification of mao ' s poetry , "even lack of etiquettes, coition could happen without prohibition. ...say men over 30, women over 20, as they have reached the marriageable age, they can make love even etiquettes are not prepared so as to bread descendants." That is to say, in the second month of spring, older young men and women can talk with each other freely and pledge to marry without the permission of parents, without completion of six steps leading to a feudal marriage. But even the six steps were not prepared, they could date and make love with the one they love as their personal willingness rather than without limitations, optionally doing sex outdoors, let alone at the "temple of religious ritual of mulberries".

In view of this, the meaning of amid mulberries, the temple and their related social customs can be be roughly recognized: amid mulberries is a place can be found anywhere , having important position in People's Daily life. Given the important functions of mulberry in the people's livelihood, people pay a lot of attention to it, then it is understandable wherein men and women meet and talk about their important affair of a final settlement in life. If both sides agree amid mulberries, they can go to a place more solemn-the temple to ask God's blessing. Six steps of marriage not prepared, getting God's blessing is also a very good thing.

\section{The Emotional Appeal of the Poem}

Now that we understand who is the man in the poem, what is the place in the poem, the emotional appeal of the poem can be readily solved.

"Where's golden thread to pick? In May field where it's thick."'Where's golden wheat to pick? In north field where it's thick." Where's mustard plant to pick? In east field where it's thick." The lyric heroes is a hardworking boy. These two beginning sentences of each chapter are described in the way of affective image and exposition: after he picked the golden thread in May field he went to pick golden wheat in north field and finally went to dig out mustard plant in east field. It is not only exposition method used in his seeing plant when working, but also elaboration of his working place. That is to say, as the main labor in family, the young fellow went to work in different places; when working, he saw the plants in front of him and thought of some other things, thus naturally bringing the following text.

"Who are you thinking of? Jiang's eldest lass I love."'Who are you thinking of? Yi's eldest lass I love."'Who are you thinking of? Yong's eldest lass I love." As above, "Meng Jiang"'Meng Yi" and "Meng Yong" are not whom the young fellow misses but three beautiful girls of the eldest in three wealthy and influential local families. Deducing from young man having to take part in labor, his 
family is not rich. He could not be close to these three girls. But he did not regret, because the one he missed is not less beautiful than them. That is to say, he takes the beauty of three girls in large house of local as reference so as to highlight the beauty of his sweetheart. It is conceivable that when the hard-working young man went to work, he thought of the same person sweetly at all the places, in all the time. Those originally heavy work is a cinch for him. The beloved thoughts make him stand out, always thoughtful with smile that people working with his also detected, they couldn't help asking, "Hello, you have anything good?" The young fellow must smiled without answer. He just remembered that time he dated with his lover, "She waits for me amid mulberries, behind the temple trysts with me and sees me off on River Qi?"

All three chapters end up with this, it is easy to see how hard to forget this date means to him: "she waits for me amid mulberries", dear girl, she was waiting for me amid mulberries, the sweet appearance really let one love. After two met and talk for a while amid mulberries, the girl invited the boy to the temple:"behind the temple tryst with me". They talked and took a walk, arriving the temple unconsciously. Just as above, the temple is a place for religious ritual of mulberries, a solemn place for holy ritual of mulberries. Even there were symbolic coition rite during the ceremony, it can not be viewed as a place for coition. It is just a place for praying for God's blessing after they found each other congenial. Just as the student of Ren Huisheng said in Cultural Interpretation of Amid Mulberries, the Book of Songs, it is just a place for praying for God's blessing after they found each other congenial. Time went always quickly when the two were together. The sweet dating time passed quickly. When parting, girl saw the young man along off to the edge of River Qi:"See me off on River Qi".

From the form, these three words is a matter of moral. The first two sentences are in five-character with relatively faster rhythm, implying a meaning of sweetness when two met, time passed unconsciously; the last sentence is in seven-character, originating from "see me off on River Qi", it is originally the same as the first two sentences as for the structure and when adding "zhi" and "yi", suddenly the tone and rhythm were slowed. This shows they didn't want to leave each other when seeing off.

At this point, it is clear that this poem is not the commonly said pornograhic poem nor a poem for a rounder who felt proud to boast about after making love with beautiful girl but a sweet memory after an infatuated man dating with his lover.

Confucius once said, "to conclude three hundred of songs in the Book of Songs in a word, that is, benevolences." It is true for this.

\section{Acknowledgement}

This article is the 1503th items of the cultivation project of 2014 Teaching achievement prizes at the Guangdong education in Guangdong province(higher education), this project belongs to the third type. The project name: Higher vocational colleges perfect the Chinese excellent traditional culture education research-take classical Chinese poetry as example.

\section{References}

[1] Zhu zi-qing, Chinese song, writers publishing house, 1957:167

[2] Ren Hui Sheng, Cultural Interpretation of Amid Mulberries, the Book of Songs, culture research on River Qi

[3] Chen Bing Liang, Myth, Ceremony and Literature, TaiPei Linking Publishing Company, 1985: 95-96

[4] Guo Mo Ruo, the First Volume of Guo Mo Ruo Corpora, Science publishing 1982:62

[5] Jin Ye Yan, Jin Jun Hua, The custome of sacrifice and commit adultery in Gao Mei-on the theme of the poetry Amid Mulberries, Master Pieces Review 2011[11]8-9 